\title{
Structural and Electrical Characterization of Sintered Silicon Nitride Ceramic
}

\author{
Imran Khan, M. Zulfequar* \\ Department of Physics, Jamia Millia Islamia, New Delhi, India. \\ Email: mzulfe@rediffmail.com
}

Received December 28 $8^{\text {th }}, 2010$; revised March 28 $8^{\text {th }}, 2011$; accepted May $5^{\text {th }}, 2011$.

\begin{abstract}
The electrical conduction phenomena, dielectric response and microstructure have been discussed in sintered silicon nitride ceramics at different temperature and frequencies. Microstructure and phase of the sintered samples was investigated by Scanning Electron Microscope (SEM) and X-ray diffractometer (XRD). The electrical conductivity, dielectric constant and dielectric loss increases exponentially with temperature greater than $600 \mathrm{~K}$. The dielectric constant and loss have been measured in the frequency range $100 \mathrm{~Hz}$ to $1 \mathrm{MHz}$. The a.c. conduction studies in the audio frequency range $500 \mathrm{~Hz}$ to $1 \mathrm{MHz}$ indicates that the conduction may be due to the electronic hopping mechanism. Silicon Nitride ceramics became dense after sintering. The effect of grain size and role of phase on electrical and dielectric properties have been discussed. These types of samples can be used as a high temperature semi conducting materials for device packaging.
\end{abstract}

Keywords: Silicon Nitride, D.C. and A.C. Conductivity, Dielectric and Structural Properties

\section{Introduction}

Silicon nitride-based ceramics have many excellent properties, high strength and relatively high fracture toughness, good wear resistance, good oxidation resistance and good corrosion resistance. For some time, they have been under consideration as high-performance structural materials because of their superior thermal shock resistance relative to oxide ceramics [1]. Silicon Nitride has been densified with sintering additives because of the highly covalent Si-N bonding. After sintering, these additives remain as the amorphous grain boundary phase, which severely deteriorates the high-temperature mechanical behavior of Silicon Nitride ceramics [2]. Dielectric films of silicon nitride ceramics play an integral role in nearly every semiconductor device and integrated circuit. Among this Silicon Nitride ceramic is used as a gate dielectric layer, diffusion barrier and optoelectronic-integrated circuits [3-5]. Low-density porous silicon nitride [6-12] ceramic is an important material with properties including low dielectric constant $\left(\varepsilon^{\prime}=2.5\right.$ to $8, \tan \delta \leq 3 \times 10^{-3}$ ), good mechanical, high resistance to rain erosion and sand erosion. Hence, low-density porous silicon nitride ceramic is also a candidate for application in radome materials [13]. Microstructural control of the interface and interlayer requires a complex interplay between initial composition and postheating transformations. The controlled crystallization of refractory secondary phases from the remaining oxynitride liquid generally results in an improvement of the high-temperature resistance of sintered $\mathrm{Si}_{3} \mathrm{~N}_{4}$ ceramics [14-16]. Nowadays most silicon nitride ceramics are prepared using $\alpha-\mathrm{Si}_{3} \mathrm{~N}_{4}$ powders. In silicon nitride ceramics, the microstructure is similar to whisker-reinforced ceramic composites, with large rod like $\beta-\mathrm{Si}_{3} \mathrm{~N}_{4}$ grains as the reinforcing agents [17]. The effect of microstructure or grain size on dielectric properties are also already discussed [18]. In earlier studies on the micro structural characterization of silicon nitrides ceramics, it is noted that all of them are conducted at relatively low TEM/SEM magnifications and therefore are limited to the examination of the general microstructure. J. D Walten, P. Popper and J. S. Throp $[19,20]$ reveal the kinetics of densification, mechanical, electrical and thermal properties of $\mathrm{Si}_{3} \mathrm{~N}_{4}$ has been studied. However no such systematic effort had been made on the electrical conductivity and dielectric properties of silicon nitride ceramic.

The electrical conductivity and dielectrical measurement are very important to check the insulating ability and dielectric losses particularly at high temperatures. The emphasis of the research, in particular, is on the characterization of the grain-boundary microstructure by 
electron imaging and to determine the electrical conductivity, dielectric constant and loss of sintered silicon Nitride ceramics.

\section{Experimental Procedure}

The samples prepared by grinding $\alpha$-phase Silicon Nitride (pure 99.999\%), purchased from Alfa Aesar (A Johnson Matthey company USA) and then the powders made into pallet using Hydraulic press at a pressure of $100 \mathrm{MPa}$. The material used in this investigation was sintered Silicon-nitride. Sintering was carried out in an alumina crucible heated by a graphite heating element in digital programmable furnace at the rate of $15^{\circ} \mathrm{C}$ per min. as an initial constant heating rate from room temperature to $900^{\circ} \mathrm{C}$ for $8 \mathrm{hrs}$, then to $950^{\circ} \mathrm{C}$ at the same constant heating rate for $2 \mathrm{~h}$ under normal pressure. For high temperature sintering up to $1450^{\circ} \mathrm{C}$ for $12 \mathrm{~h}$ at the rate of $15^{\circ} \mathrm{C}$ per min. we use muffle furnace. The samples then cooled from $1450^{\circ} \mathrm{C}$ to room temperature at a same rate. For dc conductivity measurement, the samples were mounted in a specially designed metallic sample holder where a vacuum of about $10^{-3}$ Torr could be maintained throughout the measurement. The thicknesses of samples were $1.02 \mathrm{~mm}$ and diameter $\sim 10 \mathrm{~mm}$. A dc voltage of 30 volts was applied across the samples and resulting current was measured by a pico-ammeter (Keithley, model 6485). The temperature is measured by mounting a chromel-alumiel thermocouple near the sample. Before the I-V characteristics measurement, the samples were annealed at $100^{\circ} \mathrm{C}$ in vacuum to avoid the effect of moisture. Dielectric measurements were performed by a Wayne Kerr LCR Meter (model-4300) in audio frequent- cies range of $100 \mathrm{~Hz}$ to $1 \mathrm{MHz}$ as well as in the temperature range $300 \mathrm{~K}$ to $1000 \mathrm{~K}$. In order to observe the morphology of $\mathrm{Si}_{3} \mathrm{~N}_{4}$ samples, scanning electron microscopy (SEM) was used. SEM analyses were carried out on surfaces of samples using a Scanning Electron Microscope (JEOL model JSM 6380). The specimens were silver paste coated in order to avoid charging effects. The crystalline phases present in the sintered ceramics materials were identified by X-ray powder diffraction PXRD (Powder X-Ray diffractometer) (PANalytical X-Ray Diffractometer with PW1830 Generator) (Ni-flltered $\mathrm{Cu} \mathrm{K \alpha}$ radiation; $\lambda=1.5406 \AA$ ) [21].

\section{Result and Discussion}

\subsection{Conductivity}

To measure the DC conductivity $\left(\sigma_{d c}\right)$ of sintered Silicon Nitride ceramic, the temperature dependent current has been measured. The dc conductivity is plotted as a function of temperature as shown in Figure 1. In the temperatures region $(T<625 \mathrm{~K})$, the de conductivity is nearly temperature independent. In the higher temperatures region $(T>625 \mathrm{~K})$, the dc conductivity increases exponentially with temperature.

The Arrhenius behavior of the $d c$ conductivity can be expressed by the usual relation

$$
\sigma_{d c}=\sigma_{0} \exp \left(-\frac{\Delta E_{d c}}{K T}\right)
$$

where $\sigma_{0}$ is the pre-exponential factor, $\Delta E_{d c}$ is the activation energy for $d c$ conductivity and $k$ is Boltzmann constant. The (I-V) curve is linear at room temperature which shows the ohmic behaviour of the contact. The

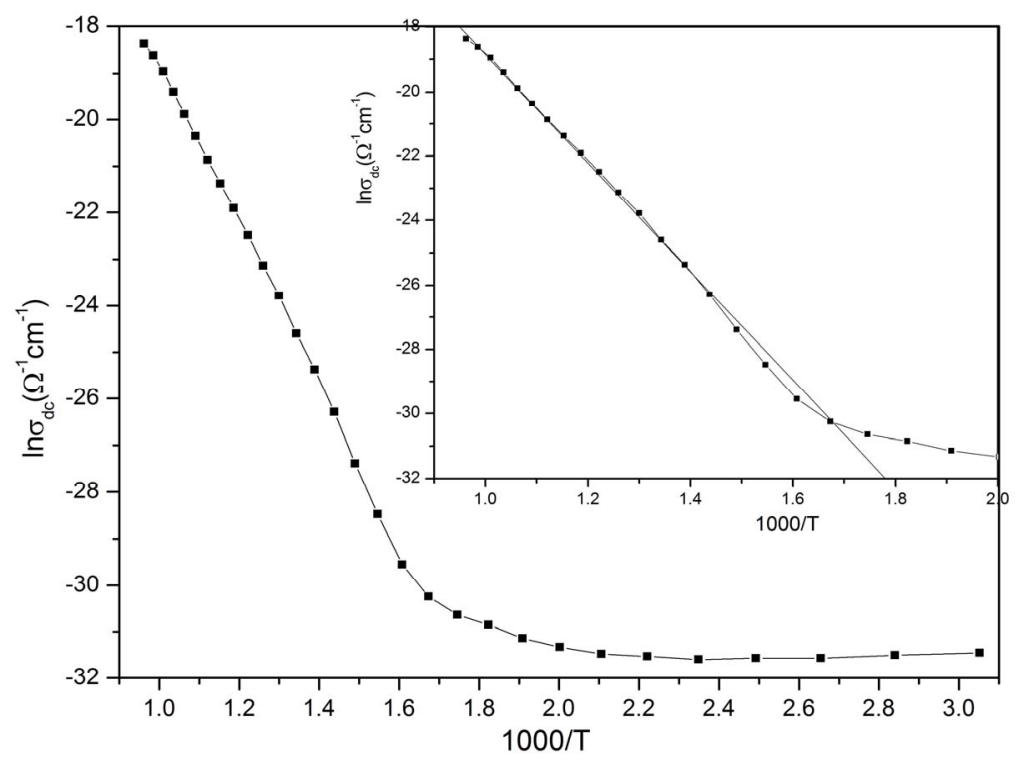

Figure 1. Temperature dependent dc conductivity of silicon nitride ceramics. 
lower temperature $(<625 \mathrm{~K})$ the behaviour of $d c$ conductivity suggested by variable-range hopping conduction. At high temperature $(>625 \mathrm{~K})$, in the thermal activated conduction region, formation of large number of charge carriers within the energy gap; start to participate in the conduction mechanism. The pre-exponential factor $\left(\sigma_{0}\right)$ depends on the mobility and concentration of charge carriers which shows that the low value of pre- exponential factor $\left(\sigma_{0}\right)$ indicates the presence of contribution of localized states. Here the improvement in conductivity can be attributed to an increase in the mobility of the charge carriers. The electrical parameters calculated from the "least-square straight-line fits" using Equation (1) is given in Table 1. The high covalence of the principal Si-N bonds, leads to the formation of substantial additional charge density re-distribution and finally increase the conductivity with temperature [22].

The aspect of this charge hopping mechanism is that the electron or hole tends to associate with local defects. The activation energy for charge transport may also include the energy of free hole from its position next to the defects $[23,24]$, and conduction occurs by phonon-assisted hopping between the localized states. The electrical conduction of the sample follows a mechanism in which the electron or hole may from one localized site to the next, and the surrounding molecules respond to this perturbation with structural changes and the electron or hole is temporarily trapped in the potential well. The electron resides at this site until it is thermally activated migrate to another site $[25,26]$. The activation energy $\Delta \mathrm{E}$ in the high-temperature region calculated from the slope, required for the movement of the electron or hole. The electron trapped in such a potential well requires activation energy to overcome a barrier of a height equal to the binding energy of the polaron in order to move to the neighboring site. The electrical conductivity of the sintered samples may form the basis for designing a new class of solid electrolytes and fuel cells applications with elevated operating characteristics.

\subsection{Dielectric Properties}

The alternative representations of the AC response of silicon nitride material are: dielectric permittivity $\varepsilon^{*}(\omega)$ and electrical conductivity $\sigma^{*}(\omega)$. In the presented work the measured quantities are the capacitance

Table 1. Electrical parameters at $T=800 \mathrm{~K}$ and $\mathrm{F}=500 \mathrm{~Hz}$.

\begin{tabular}{ccc}
\hline Function & At $1000 \mathrm{~K}$ & At $625 \mathrm{~K}$ \\
\hline$\sigma_{\mathrm{dc}}$ & $6.45 \times 10^{-9}\left(\Omega^{-1} \mathrm{~cm}^{-1}\right)$ & $1.61 \times 10^{-13}\left(\Omega^{-1} \mathrm{~cm}^{-1}\right)$ \\
$\Delta \mathrm{E}$ & $1.48 \mathrm{eV}$ & $0.16 \mathrm{eV}$ \\
$\sigma_{0}$ & $2.23 \times 10^{-16}\left(\Omega^{-1} \mathrm{~cm}^{-1}\right)$ & $2.40 \times 10^{-14}\left(\Omega^{-1} \mathrm{~cm}^{-1}\right)$ \\
\hline
\end{tabular}

$C$ and dissipation factor $D$. They have the transformation relationships described as below. The real part dielectric constant $\left(\varepsilon^{\prime}\right)$ and imaginary part dielectric loss $\left(\varepsilon^{\prime \prime}\right)$ of the dielectric permittivity are extracted using the established relationships:

$$
\varepsilon^{\prime}=\varepsilon_{0} C \cdot A / d \text { and } \varepsilon^{\prime \prime}=D \cdot \varepsilon^{\prime}
$$

The $A C$ conductivity $\sigma$ has been calculated by the relation

$$
\left.\begin{array}{l}
\sigma_{a c}=\sigma_{T}+\sigma_{d c} \\
\sigma=\varepsilon_{0} \varepsilon^{\prime \prime} \omega
\end{array}\right\}
$$

where $d$ is the thickness, $A$ is the cross-sectional area of the sample, $\varepsilon_{0}$ is the permittivity of the vacuum and $\omega$ is the angular frequency. Frequency and temperature dependence dielectric parameters $\left(\varepsilon^{\prime}\right.$ and $\left.\varepsilon^{\prime \prime}\right)$ of the sintered silicon nitride ceramics are investigated in the temperature range $(300 \mathrm{~K}-1000 \mathrm{~K})$ at frequencies $(100$ $\mathrm{Hz}$ to $1 \mathrm{MHz}$ ). Figure 2 and Figure 3, show the temperature dependent dielectric constant $\left(\varepsilon^{\prime}\right)$ and dielectric loss $\left(\varepsilon^{\prime \prime}\right)$ at different frequencies $(100 \mathrm{~Hz}$ to $1 \mathrm{MHz})$. The values of $\varepsilon^{\prime}$ and $\varepsilon^{\prime \prime}$ from room temperature to $(>625 \mathrm{~K})$ remain almost independent of temperature. As the temperature are increases, $\varepsilon^{\prime}$ and $\varepsilon^{\prime \prime}$ increase quite appreciably with temperature.

The increase in the dielectric constant and loss are determined by the bulk conductivity of the grains, which increases as the frequency decreases as shown in Figure 4 and Figure 5. It was established that a higher dielectric constant is typical for materials based on $\mathrm{Si}_{3} \mathrm{~N}_{4}$ from furnace synthesis. We have observed that this is connected with the state of the grain boundaries in the sintered materials. It was established that recrystallization processes practically do not occur during sintering of these materials; so as a result of interphase interaction between the $\mathrm{Si}_{3} \mathrm{~N}_{4}$ crystallites with the other phases, their surface layer varies substantially to a depth determined by the activity of the diffusion processes. The major crystalline phases present in the products were $\alpha-\mathrm{Si}_{3} \mathrm{~N}_{4}, \beta-\mathrm{Si}_{3} \mathrm{~N}_{4}$, and $\mathrm{Si}_{2} \mathrm{ON}_{2}$ in addition to starting phase [27]. This leads to formation of energy levels at the grain boundaries and the electronic polarization increases.

During grain growth, more perfect crystallites are formed without a defective outer shell, which reduces their conductivity and thus the polarizability. The dielectric loss $\left(\varepsilon^{\prime \prime}\right)$ arise due to the dielectric polarization and $\mathrm{dc}$ conduction. To study the origin of the dielectric loss in the operating temperature range, the $d c$ contribution was calculated using the relation;

$$
\varepsilon_{D C}^{\prime \prime}=\sigma_{D C} / \varepsilon_{0} \omega
$$

The calculated and observed dielectric loss $\left(\varepsilon^{\prime \prime}\right)$ are plotted in Figure 6 with temperature. It is observed that 


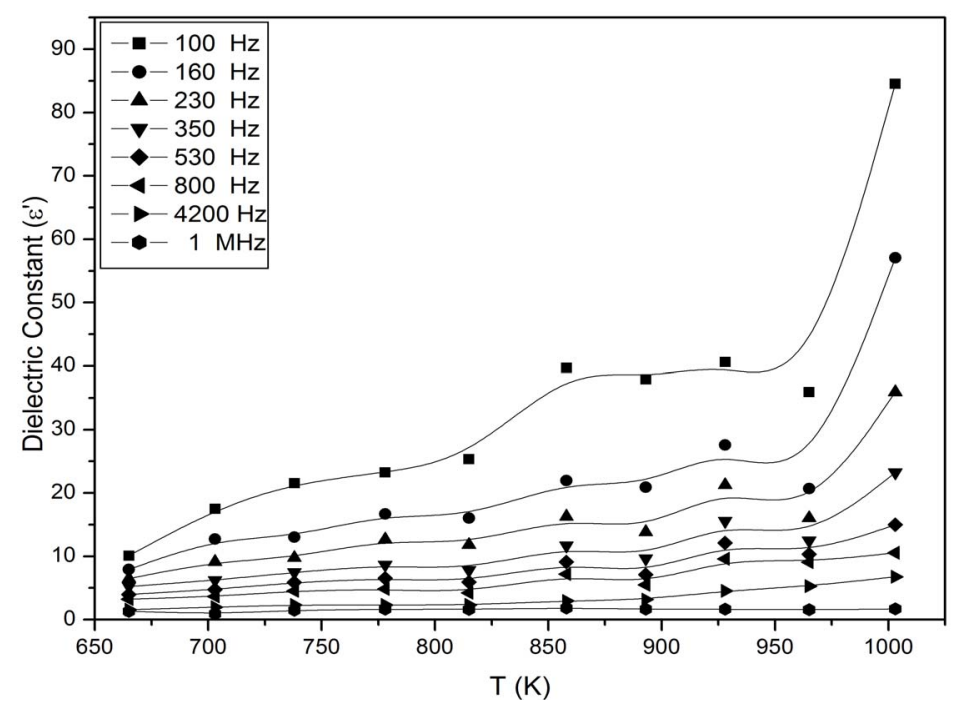

Figure 2. The dielectric constant $\left(\varepsilon^{\prime}\right)$ vs. temperature.

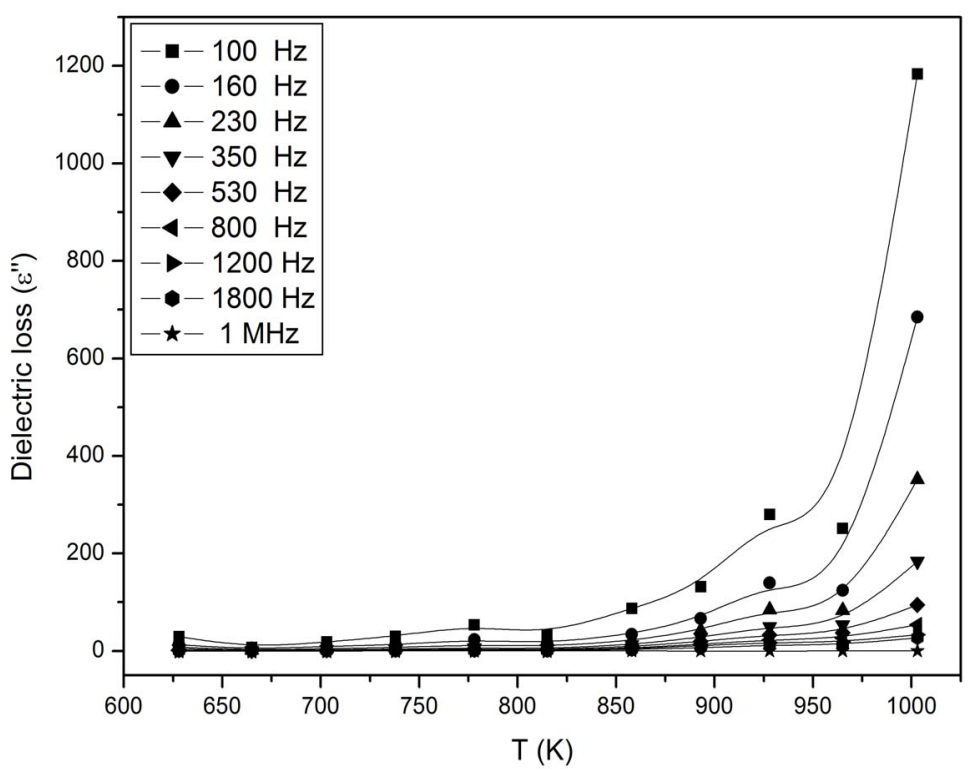

Figure 3.Tthe dielectric loss $\left(\varepsilon^{\prime \prime}\right)$ vs. temperature.

the dc conduction loss is less than the observed loss.

The variation of $\varepsilon^{\prime}$ and $\varepsilon^{\prime \prime}$ with temperature and frequency can not, therefore, be attributed to the dc conduction losses. The formation of defects in the structure at high temperature is expected because of recrystallization. Therefore, the samples should possess vacancies due to recrystallization and generating charge carriers. These results show insignificant conductive loss $\left(\varepsilon_{D C}^{\prime \prime}\right)$ over the entire temperature range. However, the temperature dependence of the dielectric loss $\left(\varepsilon^{\prime \prime}\right)$ for high temperatures region $(T>800 \mathrm{~K})$ shows the apparent increase with increasing temperature, due to the recrystallization and phase transition. Hence the dielectric loss cannot be attributed to dc conduction in the entire temperature range. It is attributed due to space charge polarization.

Figure 7, shows initially (in lower temperature region) weak temperature and frequency dependent of AC conductivity. But by increasing the temperature, the dependence of temperature and frequency becomes more significant.

The frequencies dependent ac conductivity shows Figure 8, which follows the power law as given below

$$
\sigma_{a c} \propto A \omega^{S}
$$

Here, $A$ is a constant and $s$ is the frequency dependent exponent parameter calculated from the slop of the straight line. The value of $s$ is found 0.75 which is in between $0.5-1.0$ in the temperature range $(300 \mathrm{~K}-1000$ 


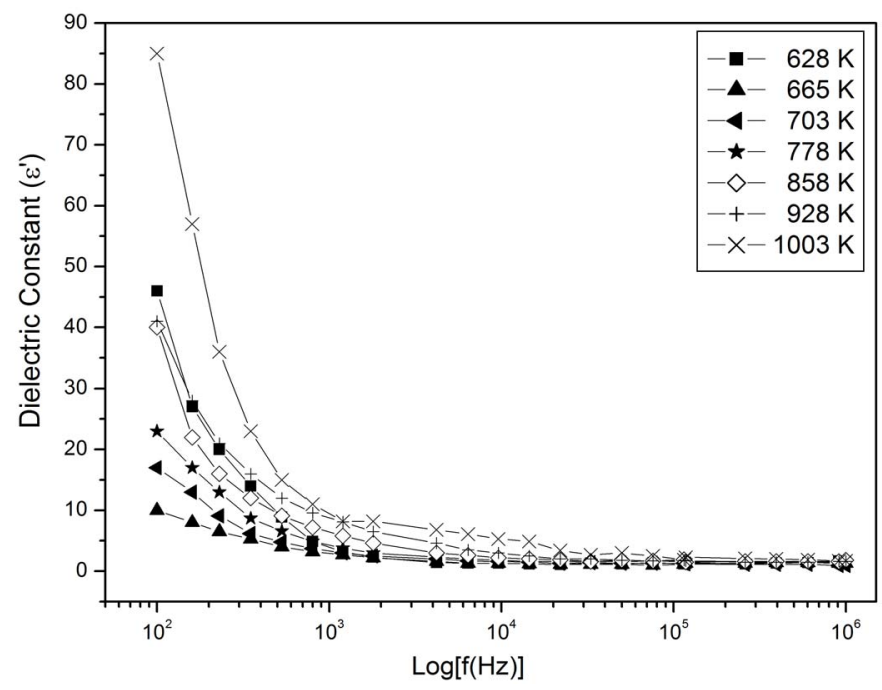

Figure 4. Frequency dependent dielectric constant $\left(\varepsilon^{\prime}\right)$.

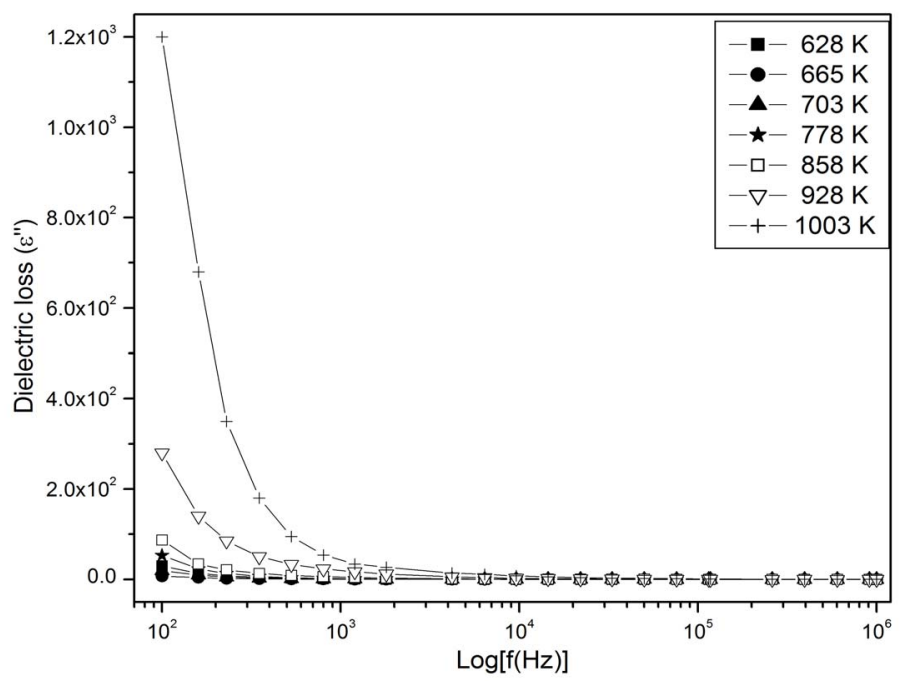

Figure 5. Frequency dependent dielectric loss $\left(\varepsilon^{\prime \prime}\right)$.

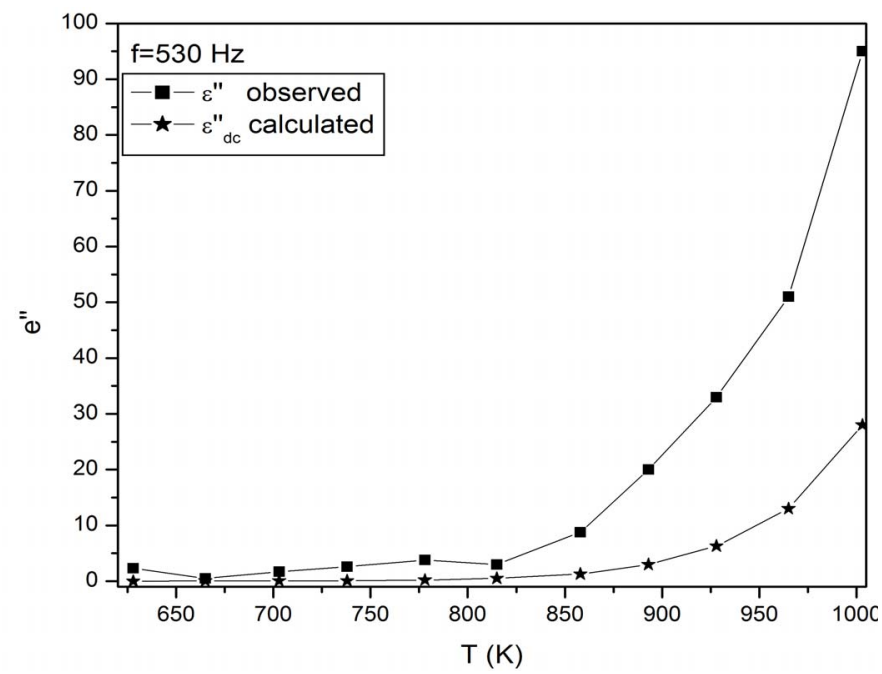

Figure 6. Temperature dependence conduction loss. 


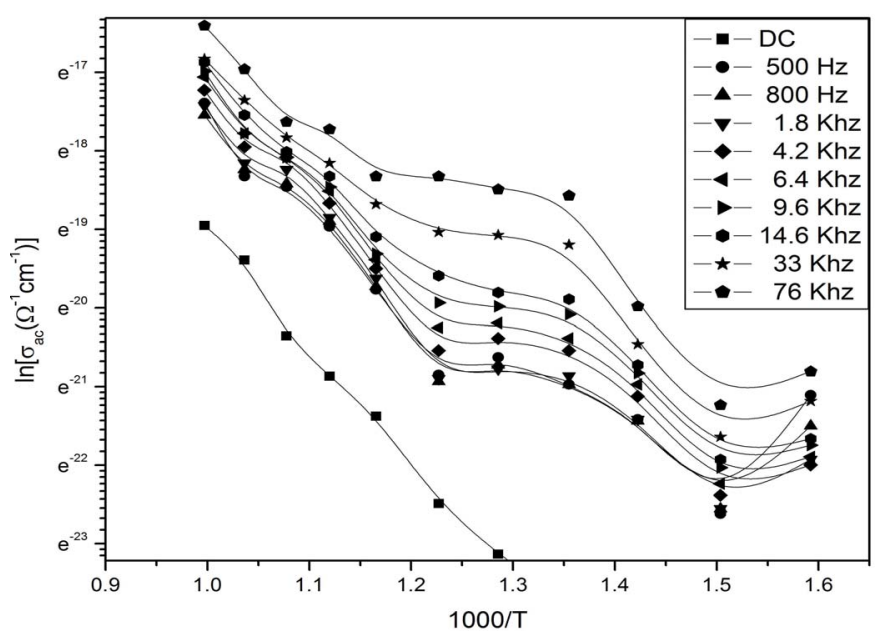

Figure 7. Temperature dependent a.c. conductivity at various frequencies.

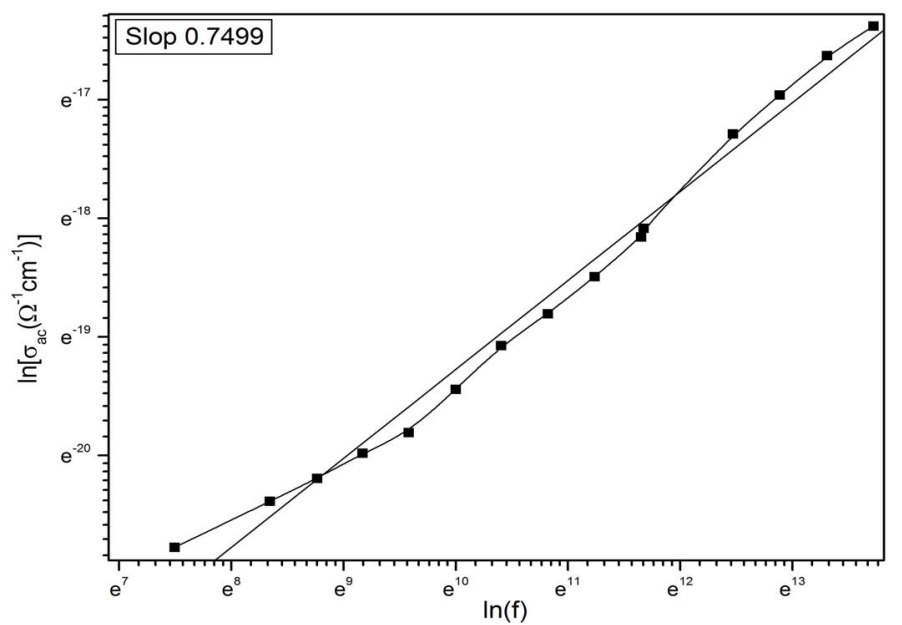

Figure 8. Frequency dependent a.c. conductivity.

$\mathrm{K})$. The all calculated dielectric parameters are given in Table 2. We show that the conduction in $\mathrm{Si}_{3} \mathrm{~N}_{4}$ ceramic is hopping conduction which is due to the space charge polarization.

The variation in $\varepsilon^{\prime}$ and $\sigma_{a c}$ with temperature $\&$ frequencies may therefore, be attributed to space charge polarization whose possibilities is quite large in the present case. As we are dealing with polycrystalline samples the grain boundaries and various other structural defects may have different condition and a heterogeneous system is formed. Due to different region of conductivity the charge may be accumulated which may result into large polarization at high temperature. The dielectric dispersion observed in the present case may, therefore, be understood in terms of space charge polarization. Based on the simplest Maxwell-Wagner two-layer capacitor model, the behaviour of such a capacitor under AC field has been analyzed. It was found that both the overall dielectric constant and the conductivity depend on the fre- quency, the relative difference in layer thickness, the dielectric constant, and the conductivity between the two layers [28]. It is well known [29,30] that dielectric properties are strongly dependent on the dielectric polarizability, porosity and the grain sizes. The dielectric constant decreases with increasing porosity, and the geometrical nature of the pores is also a factor that affects the dielectric constant. Thus by measurement of the real part of relative permittivity it is not possible to distinguish between the effects of interfacial and orientational polarizability.

From equation

$$
\varepsilon^{\prime}=\varepsilon_{\infty}+\frac{\varepsilon_{s}-\varepsilon_{\infty}}{1+\omega^{2} \tau^{2}}
$$

We also have

$$
\varepsilon^{\prime \prime}=\frac{1}{\omega C_{0}\left(R_{1}+R_{2}\right)} \cdot \frac{1-\omega^{2} \tau_{1} \tau_{2}+\omega^{2} \tau\left(\tau_{1}+\tau_{2}\right)}{1+\omega^{2} \tau^{2}}
$$


Table 2. Dielectric parameters at $T=800 \mathrm{~K}$ and $\mathrm{F}=500 \mathrm{~Hz}$.

\begin{tabular}{ccccc}
\hline Function & \multicolumn{2}{c}{ At $1000 \mathrm{~K}$} & $\mathrm{~F}=160 \mathrm{~Hz}$ & At $625 \mathrm{~K}$ \\
\hline$\varepsilon^{\prime}$ & $\mathrm{F}=160 \mathrm{~Hz}$ & $\mathrm{~F}=1 \mathrm{MHz}=1 \mathrm{MHz}$ \\
$\varepsilon^{\prime \prime}$ & 56.94 & 2.00 & 27.1 & 1.74 \\
$\sigma_{\mathrm{ac}}\left(\Omega^{-1} \mathrm{~cm}^{-1}\right)$ & 673.03 & 1.53 & 10.13 & 0.16 \\
$\varepsilon_{\mathrm{ac}}^{\prime}$ & $2.5 \times 10^{-8}$ & $8.2 \times 10^{-8}$ & $3.5 \times 10^{-10}$ & $3.8 \times 10^{-10}$ \\
\hline
\end{tabular}

Hence

$$
\varepsilon^{\prime \prime}=\frac{1}{\omega C_{0}\left(R_{1}+R_{2}\right)}+\frac{\left(\varepsilon_{s}-\varepsilon_{\infty}\right) \omega \tau}{1+\omega^{2} \tau^{2}}
$$

where

$$
\left\{\begin{array}{l}
\varepsilon_{s}=\frac{\tau_{1}+\tau_{2}-\tau}{C_{0}\left(R_{1}+R_{2}\right)} \\
\tau=\frac{R_{2} \tau_{1}+R_{1} \tau_{2}}{R_{1}+R_{2}}
\end{array}\right.
$$

And $R_{1}$ and $R_{2}$ are the resistance of grain boundary layers and the grain. The second term of Equation (8) is exactly the Debye relaxation equation, but there is an additional term inversely proportional to frequency. This means that the losses, represented by $\varepsilon^{\prime \prime}$, tend to infinity as $\omega$ tends to zero. Thus the case of interfacial polarizability may be distinguished from Debye relaxation by observing the variation of $\varepsilon^{\prime \prime}$ below the relaxation frequency. In the Debye case $\varepsilon^{\prime \prime}$ drops towards zero as the frequency is lowered.

In general, the resistivity of boundary layers $\left(\rho_{1}\right)$ is larger than the resistivity of the grain $\left(\rho_{2}\right)$, Consider $x \ll 1 \quad \& \quad \rho_{1} \gg \rho_{2}$ then

$$
\tau=\varepsilon_{0} \varepsilon_{2}^{\prime} \frac{\rho_{1} \rho_{2}}{x \rho_{1}+\rho_{2}}
$$

It is clear from equation that the relaxation time $(\tau)$ for the interfacial polarization is proportional to the product of the resistivity of the two layers. The frequency at which these types of polarization become effective which therefore depends upon the resistivity $\rho_{2}$ of the grain. As the resistivity decreases at higher temperature, this type of polarization becomes quite effectives at these frequencies. Due to the decrease in resistivity, the dielectric constant $\left(\varepsilon^{\prime}\right)$ increase and dielectric loss $\left(\varepsilon^{\prime \prime}\right)$ also increases.

From the above discussion, one can interpreted that the space charge polarisation may to predominate the polarisation mechanism in Silicon Nitride Ceramic.

\subsection{Structural Characterization}

In Figure 9, the microstructures of the sintered samples are shown in the SEM images of fractured surface of the samples. The volume of pores and grain size can be seen clearly. During sintering, silica on the surface of $\mathrm{Si}_{3} \mathrm{~N}_{4}$ and some of the nitride forms an oxynitride at a high temperature, which promotes the densification of the material. The surface of this particular elongated grain shows distinct evidence of crack growth along the surface of the grain. Such a growth mode helps to produce a complex crack path, which in turn contributes to crack deflection and bridging, thereby improving the toughness of these ceramics. The large grains surrounding some fine grains can form open as well as closed pores $[16,17]$. This effect results in the rearrangement stage and rapid initial densification. So these dense Silicon Nitride ceramics samples confirm certain electrical and dielectrical properties at high temperature.

The X-ray diffraction of $\mathrm{Si}_{3} \mathrm{~N}_{4}$ ceramics is shown in Figure 10. There are ten major peaks indicate the $\alpha$-phase of silicon nitride five peaks indicate $\beta$-phase of silicon nitride and four peaks of another phase of silicon oxy nitride (SiON). X-ray diffraction Pattern indicates that the sintered samples basically preserve the characters of the starting powders. The sintering mechanism up to some extent, confirms certain electrical properties of the sintered samples [31,32].

\section{Conclusions}

We have discussed the electrical conductivity of Silicon Nitride Ceramic $\left(\mathrm{Si}_{3} \mathrm{~N}_{4}\right)$ ceramics in the temperature range $(300 \mathrm{~K}$ to $1000 \mathrm{~K})$. We have studied the dc conductivity and dielectric parameters ( $\varepsilon^{\prime}$ and $\varepsilon^{\prime \prime}$ ) of the sintered silicon nitride ceramics with structural characterization. The electrical properties are significantly affected with temperature as well as frequency. The electrical conduction of the $\mathrm{Si}_{3} \mathrm{~N}_{4}$ sample follows a mechanism in which the electron or hole may from one localized site to the next. The a.c. conduction studies in the frequency range $500 \mathrm{~Hz}$ to $1 \mathrm{MHz}$ indicates that the conduction may be due to the large polarization at high temperature. As it is shown from experimental results that sintered silicon nitride ceramics material shows very good results by high polarizability over entire frequency range. The electrical and dielectric properties are also depended on the grain size. The qualitative dielectric dispersion observed in the present case confirms space charge polarization. During sintering the diffusion processes leads to formation of surface energy levels at the grain boundaries and enhance the polarization. The grain growth formed more perfect crystallites without a 

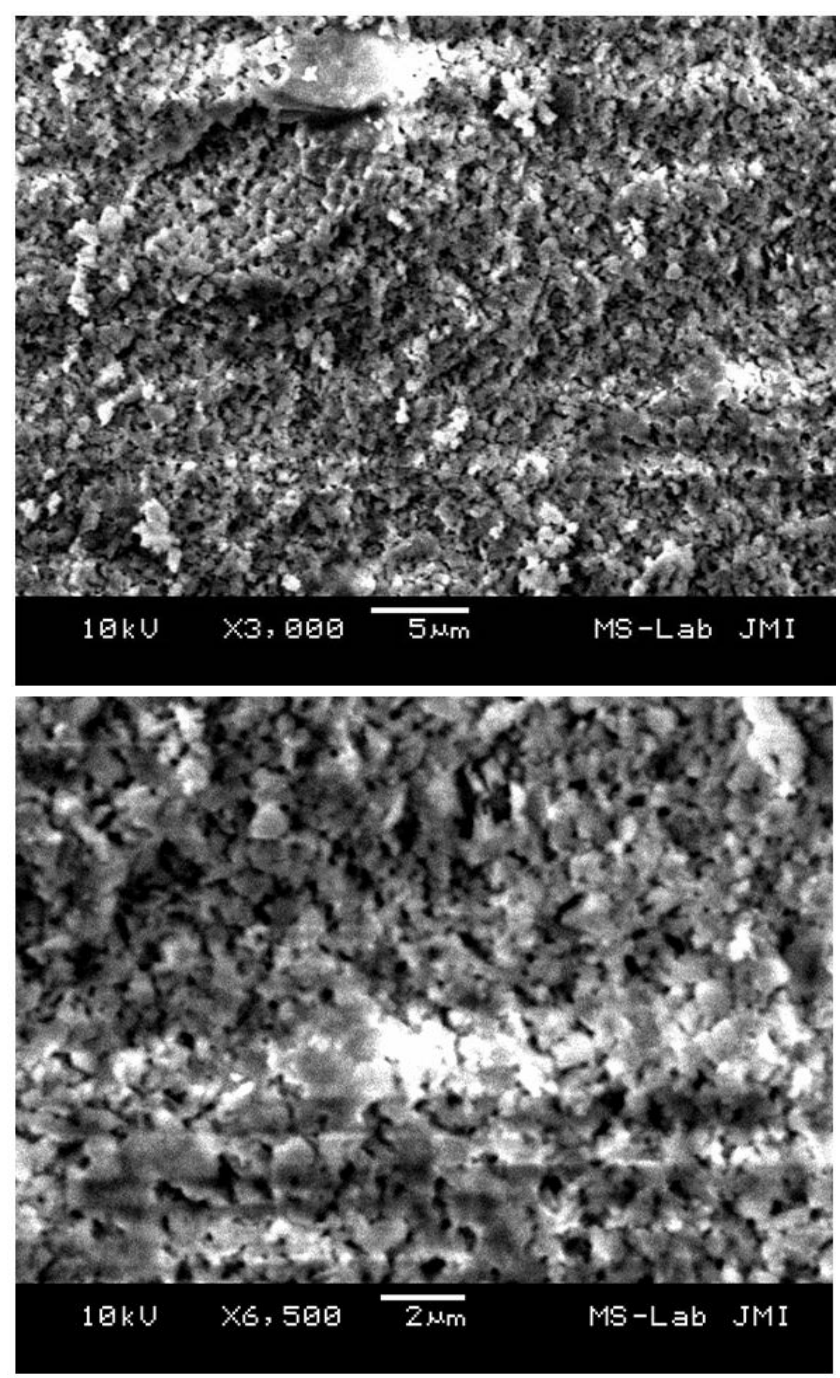

Figure 9. Grain boundaries in sintered silicon nitride ceramics at $1450^{\circ} \mathrm{C}$.

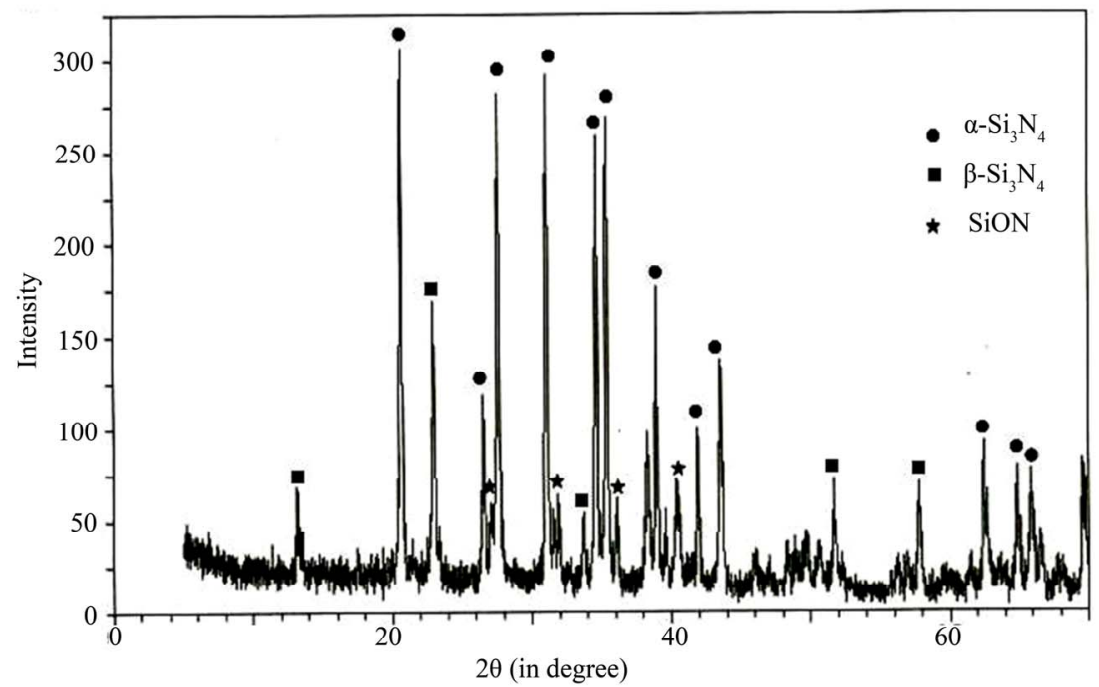

Figure 10. X-RD pattern of sintered silicon nitride ceramics. 
defective outer shell. SEM images confirm the rearrangement stage and rapid initial densification and X-ray diffraction pattern indicates that the sintered samples basically preserve the characters of the starting powders. These types of samples can be used as a high temperature semi conducting materials.

\section{REFERENCES}

[1] H.-J. Choi, J.-G. Lee and Y.-W. Kim, "High Temperature Strength and Oxidation Behavior of Hot-Pressed Silicon Nitride-Disilicate Ceramics," Journal of Materials Science, Vol. 32, No. 7, 1997, pp. 1937-1942.

[2] Y. S. Zheng, K. M. Knowles, J. M. Vieira, A. B. Lopes and F. J. Oliveira, "Microstructure, Toughness and Flexural Strength of Self-Reinforced Silicon Nitride Ceramics Doped with Yttrium Oxide and Ytterbium Oxide," Journal of Microscopy, Vol. 201, No. 2, 2001, pp. 238-249. doi:10.1046/j.1365-2818.2001.00839.x

[3] I. Khan and M Zulfequar, "Effect of Tellurium on Electrical and Structural Properties of Sintered Silicon Nitride Ceramics," Physica B, Vol. 404, No. 16, 2009, pp. 23953400. doi:10.1016/j.physb.2009.04.050

[4] R. D. Gould, S. A. Awan, "DC Conductivity in RF Magnetron Sputtered Gold-Silicon Nitride-Gold Sandwich Structures," Thin Solid Film, Vol. 398-399, 2001, pp. 454-459. doi:10.1016/S0040-6090(01)01383-9

[5] M. C. Hugon, F. Delmotte, B. Agiusa and J. L. Courant, "Electrical Properties of Metal-Insulator-Semiconductor Structures with Silicon Nitride Dielectrics Deposited by Low Temperature Plasma Enhanced Chemical Vapor Deposition Distributed Electron Cyclotron Resonance," Journal of Vacuum Science \& Technology A, Vol. 15, No. 6, 1997, pp. 3143-3154.

[6] J. H. She, J. F. Yang and D. J. Daniel, "Thermal Shock Behavior of Isotropic and Anisotropic Porous Silicon Nitride," Journal of the American Ceramic Society, Vol. 86, No. 4, 2003, pp. 738-740.

[7] S. K. Lee, J. D. Moretti, M. J. Readey and B. R. Lawn, "Thermal Shock Resistance of Silicon Nitrides Using an Indentation-Quench Test," Journal of the American Ceramic Society, Vol. 85, No. 1, 2002, pp. 279-281.

[8] S. Toshimori, "Shock Synthesis of Cubic Silicon Nitride," Journal of the American Ceramic Society, Vol. 85, No. 1, 2002, pp. 113-116.

[9] S. F. Dennis, J. O. Elizabeth and N. N. Quynhgiao, "Paralinear Oxidation of Silicon Nitride in a Water-Vapor/ Oxygen Environment," Journal of the American Ceramic Society, Vol. 86, No. 8, 2003, pp. 1256-1261.

[10] M. Backhaus-Ricoult, V. Guerin, A. M. Huntz and V. S. Urbanovich, "High-Temperature Oxidation Behavior of High-Purity $\alpha$-, $\beta$-, and Mixed Silicon Nitride Ceramics," Journal of the American Ceramic Society, Vol. 85, No. 2, 2002, pp. 385-392.

[11] Y. Zhang, Y. B. Cheng S. Lathabai and K. Hirao, "Erosion Response of Highly Anisotropic Silicon Nitride," Journal of the American Ceramic Society, Vol. 88, No. 1, 2005, pp. 114-120.
[12] A. Zerr, M. Kempf, M. Schwarz, E. Kroke, M. Goken and R. Riedel, "Elastic Moduli and Hardness of Cubic Silicon Nitride," Journal of the American Ceramic Society, Vol. 85, No. 1, 2002, pp. 86-90.

[13] J. Barta, M. Manela and R. Fischer, " $\mathrm{Si}_{3} \mathrm{~N}_{4}$ and $\mathrm{Si}_{2} \mathrm{~N}_{2} \mathrm{O}$ for High Performance Radome," Materials Science and Engineering, Vol. 71, 1984, pp. 265-272.

[14] W. Braue, G. Wo"tting and G. Ziegler, "Influence of Sintering Conditions on Mechanical Properties at Room and High Temperatures for Selected Y-Al-Si-O-N Materials," Journal of Physics, Vol. 2, No. 47, 1986, pp. C1-341C1-345.

[15] G. D. Quinn and W. Braue, "Fracture Mechanism Maps for Advanced Structural Ceramics," Journal of Materials Science, Vol. 25, No. 10, 1990, pp. 4377-4392. doi:10.1007/BF00581096

[16] M. H. Lewis, G. Leng-Ward and C. Jasper, "Sintering Additive Chemistry in Controlling Microstructure and Properties of Nitride Ceramics," In: G. L. Messing, E. R. Fuller Jr. and H. Hausner, Eds., Ceramic Transactions, Vol. 1, Ceramic Powder Science II, Part B, American Ceramic Society, Westerville, OH, 1988, pp. 1019-1033.

[17] A. Vuckovic, S. Boskovic and L. Zivkovic, "Synthesis of 'in-Situ' Reinforced Silicon Nitride Composites," Journal of the Serbian Chemical Society, Vol. 69, No. 1, 2004, pp. 59-67. doi:10.2298/JSC0401059V

[18] M. K. Park, H. N. Kim, K. S. Lee, S. S. Baek, E. S. Kang, Y. K. Baek and D. K. Kim, "Effect of Microstructure on Dielectric Properties of $\mathrm{Si}_{3} \mathrm{~N}_{4}$ at Microwave Frequency," Key Engineering Materials, Vol. 287, 2005, pp. 247-252. doi:10.4028/www.scientific.net/KEM.287.247

[19] J. D. Walton, Journal of the American Ceramic Society, Bull. 53, 1974, p. 255.

[20] J. S. Throp and R. I. Sharif, "Dielectric Properties of Some Hot-Pressed Nitrogen Ceramics," Journal of Materials Science, Vol. 12, No. 11, 1977, pp. 2274-2280. doi:10.1007/BF00552249

[21] C. P. Gazzara, D. R. Messier, Journal of the American Ceramic Society, Vol. 78, 1977, p. 1076.

[22] I. V. Kityk and P. Mandracci, "Nonlinear Optical Effects in Amorphous-Like SiCON Films," Physics, Vol. 340, No. 5-6, June 2005, pp. 466-473.

[23] D. F. Shriver, P. W. Atkins and C. H. Langford, "Inorganic Chemistry," Freeman, New York, 1994.

[24] K. F. Purcell and J. C. Kotz, "Inorganic Chemistry," Saunders, Philadelphia, 1977.

[25] M. M. El-Nahass, H. M. Zeyada, M. M. El-Samanoudy, E. M. El-Menyawy, Journal of Physics: Condensed Matter, Vol. 18, No. 22, 2006, p. 5163. doi:10.1088/0953-8984/18/22/016

[26] F. Yakuphanoglu, Y. Aydogdu, U. Schatzschneider and E. Rentschler, "DC and AC Conductivity and Dielectric Properties of the Metal-Radical Compound: Aqua[bis(2dimethylaminomethyl-4-NIT-phenolato)]Copper(II)," Solid State Communications, Vol. 128, No. 2-3, 2003, pp. 63-67.

[27] M. Kara and A. Kerber, "Manufacture and Properties of 
Nitride Bonded Silicon Carbide Materials," Fachberichte, Vol. 72, No. 6, 1995, pp. 325-328.

[28] D. Liufu, X. S. Wang, D. M. Tu, and K. C. Kao, Journal of Applied Physics, "High-Field Induced Electrical Aging in Polypropylene Films," Vol. 83, No. 4, 1998, p. 2209. doi: $10.1063 / 1.366958$

[29] H.-J. Choia, D.-H. Hanb, D.-S. Park, H.-D. Kimc, B.-D. Hanc, D.-S. Lima and I.-S. Kim, "Erosion Characteristics of Silicon Nitride Ceramics," Ceramics International, Vol. Vol. 29, No. 6, 2003, pp. 713-719.

[30] J.-F. Yang, T. Ohji, S. Kanzaki, A. Díaz and S. Hampshire, "Microstructure and Mechanical Properties of Sili- con Nitride Ceramics with Controlled Porosity," Journal of the American Ceramic Society, Vol. 85, No. 6, 2002, pp. 1512-1516.

[31] J. Xu, D. M. Zhu, F. Luo, W. C. Zhou and P. Li, "Dielectric Properties of Porous Reaction-Boned $\mathrm{Si}_{3} \mathrm{~N}_{4}$ Ceramics with Controlled Porosity and Pore Size," Journal of Materials Science Technology, Vol. 24. No. 2, 2008, p. 207.

[32] J. A. Schneider, S. H. Risbud, and A. K. Mukherjee, "Rapid Consolidation Processing of Silicon Nitride Powders," Journal of Materials Research, Vol. 11, No. 2, February 1996, pp. 358-362. doi:10.1557/JMR.1996.0043 